\title{
Detection of genetic variation and activity analysis of the promoter region of the cattle tRNA-modified gene TRDMT1
}

\author{
Xiaohua $\mathrm{Yi}^{1}{ }^{\star}$, Shuai $\mathrm{He}^{1}{ }^{\star}$, Shuhui Wang ${ }^{1}$, Haidong $\mathrm{Zhao}^{1}$, Mingli $\mathrm{Wu}^{1}$, Shirong Liu ${ }^{1}$, and \\ Xiuzhu Sun ${ }^{2}$ \\ ${ }^{1}$ College of Animal Science and Technology, Northwest A\&F University, \\ Yangling, Shaanxi, 712100, PR China \\ ${ }^{2}$ College of Grassland Agriculture, Northwest A\&F University, \\ Yangling, Shaanxi 712100, PR China \\ ^ These authors contributed equally to this work. \\ Correspondence: Xiuzhu Sun (sunxiuzhu208@163.com)
}

Received: 21 September 2020 - Revised: 9 March 2021 - Accepted: 26 March 2021 - Published: 30 April 2021

\begin{abstract}
The tRNA modification gene in eukaryotes is relatively conservative. As an important modification gene, the TRDMT1 gene plays an important role in maintaining tRNA structural maintenance and reducing mistranslation of protein translation by methylation of specific tRNA subpopulations. Mouse and zebrafish TRDMT1 knockout experiments indicate that it may mediate growth and development through tRNA modification. However, there are no systematic reports on the function of tRNA-modified genes in livestock. In this study, Qinchuan cattle DNA pool sequencing technology was used. A $\mathrm{G}>\mathrm{C}$ mutation in the -1223 bp position upstream of the TRDMT1 translation initiator codon was found. At this locus, the dual-luciferase assay indicated that different genotypes cause differences in transcriptional activity $(P<0.05)$. Our experiment detected a natural genetic variation of a tRNA modification gene TRDMT1, which may provide potential natural molecular materials for the study of tRNA modification.
\end{abstract}

\section{Introduction}

China has a wealth of local cattle breeds, of which the top five cattle are representatives of high-quality cattle breeds, namely Qinchuan cattle, Jinnan cattle, Nanyang cattle, Luxi cattle and Yanbian cattle. Beef cattle mainly provide humans with high-protein beef products. With the improvement of people's living standards, the demand for beef and other products is also increasing. Hence, the improvement of beef cattle breeds is urgent. At present, gene-editing methods can be modified at the level of nucleobase modification, including DNA, histones, RNA, etc. which may all be useful in beef cattle breeding (Vojta et al., 2016).

RNA modification is a common phenomenon in molecular biology. Various types of RNA in cells can be modified after transcription. Many chemical modifications are conser- vative, suggesting that RNA modification is related to protein translation (Grosjean et al., 2014). In biology, tRNA is a key factor in the transition between mRNA and protein. The maturation of tRNA requires the splicing of introns and chemical modification of specific loci to mature (Hopper and Phizicky, 2003). Some tRNA-modified genes are associated with metabolic defects, including CDK5-like regulatory subunit-related protein 1 (CDKAL1), tRNA aspartate methyltransferase 1 (TRDMT1) and tRNA methyltransferase 10 homolog A (TRMT10A) (Sarin and Leidel, 2014). TRDMT1, as an RNA methyltransferase known to methylate tRNA, is recruited to DNA damage sites and required for the induction of RNA m5C (Kunert et al., 2003; Jurkowski et al., 2008; Rai et al., 2007; Chen et al., 2020). Knockout experiments confirmed that it weakly modified animal and plant DNA, but there is no significant difference between 
the knockout type and wild type in Drosophila, Arabidopsis and mice (Goll et al., 2006). Subsequently, it was found that TRDMT1 protein can form 5-methylcytidine (m5C) on tRNA and mRNA. Tuorto et al. (2012) found that the double-knocktype mouse embryonic fibroblasts have reduced proliferative capacity, and at the same time, protein synthesis is restricted. Xue et al. (2019) found that knockdown of TRDMT1 significantly inhibited HEK293 cell proliferation and migration but had no effect on clonogenic potential. The inhibitory effects could be attenuated by re-expression of TRDMT1 in HEK293 cells.

TRDMT1 is also known as Dnmt2, the most conserved member of the DNA methyltransferase family, which has been shown to methylate tRNAs (Goll et al., 2006). As a member of the epigenetic modification factor, TRDMT1 can both methylate genomic DNA and modify RNA. It has mostly been characterized as either targeting tRNA or rRNA and can be chemically modified for specific tRNA subpopulations in different eukaryotes (Schumann et al., 2020; Sibbritt et al., 2013; Bohnsack et al., 2019). Epigenetic modification is an important reason for the spatiotemporal expression of genes and also plays a key role in the growth and development of animals. The knockdown of TRDMT1 expression caused a decrease in the level of tRNA modification, and the development of animal bones, muscles and other tissues was limited, suggesting that its expression may affect the relevant life processes.

The specific modification of tRNA ensures the correct assembly of tRNA during protein translation (Pütz et al., 1994), avoiding erroneous loading. tRNA-specific modifications can maintain the stability of tRNA, and the lack of necessary modifications may lead to premature decay of tRNA, shortening its half-life period (Alexandrov et al., 2006). tRNA modification can also stabilize its structure and enhance nuclease tolerance (Schaefer et al., 2010). In addition, tRNA modification can maintain its structural and functional stability.

The occurrence of tRNA modification affects life activities by affecting the synthesis of proteins. Liu et al. (2015) reported that the DNA chemical modification factor DNMT family gene SNP locus was associated with corpus callosum mass, lean meat color and flank thickness. The tRNA modification gene is evolutionarily conserved, but most of the research exists only in the model organism such as yeast and mouse. The state of tRNA modification is associated with disease, growth and metabolism (Sarin et al., 2014; Rai et al., 2007; Barrett er al., 2008; Cătoi et al., 2015). Vitamin B12 and folic acid levels in pregnant women with TRDMT1 mutations are significantly different from those in the wildtype population, and this gene polymorphism is associated with the occurrence of congenital spina bifida in the fetus (Franke et al., 2009).

In this experiment, by detecting the mutation in the promoter region of the bovine TRDMT1 gene, fluorescent recombinant plasmids of different genotypes were constructed at this site, and the relative fluorescence intensity was analyzed by detecting the transfected $293 \mathrm{~T}$ cells. The binding and influence of the mutation site and the transcription factor were analyzed by software. Meanwhile, we detected the relative expression of TRDMTl gene in each tissue. This study provides a certain theoretical basis for the study of livestock TRDMT1 gene expression on its life activities and the study of tRNA modification in animal life processes.

\section{Materials and methods}

\subsection{DNA extraction}

A total of 224 Qinchuan cattle (2-6 years old) were collected in this research. All selected individuals were healthy and unrelated. All DNA was obtained from the blood samples by phenol chloroform (Pang et al., 2011).

\subsection{DNA pool construction}

All DNA samples were diluted to working concentration $(50 \mathrm{ng} / \mu \mathrm{L})$ according to previous report by Li et al. (2013). Three groups of 30 individuals per group were randomly composed, and each group of samples was uniformly mixed into one tube. After shaking, the mixture was centrifuged to form a DNA pool, which was used as templates for polymerase chain reaction (PCR) amplification.

\subsection{Primer design, PCR protocol and DNA sequencing}

The $5^{\prime}$ flanking region sequences of TRDMTl gene were downloaded from Ensembl (http://asia.ensembl.org/index. html, last access: 20 August 2019). As shown in Table 1, we designed a total of five pairs of primers to scan the TRDMT1 gene including the first exon and the $5^{\prime}$ flanking region totaling $1468 \mathrm{bp}$. The PCR program was set to ensure that a sufficient number of the target fragments were amplified: predegeneration at $95^{\circ} \mathrm{C}$ for $5 \mathrm{~min}$, followed by 35 cycles of denatured at $95^{\circ} \mathrm{C}$ for $30 \mathrm{~s}$, annealed at $55 / 57^{\circ} \mathrm{C}$ for $30 \mathrm{~s}$, and extended at $72^{\circ} \mathrm{C}$ for $30 \mathrm{~s}$, finally extended at $72^{\circ} \mathrm{C}$ for $10 \mathrm{~min}$. PCR amplification was performed using bovine mixed-pool DNA as a template, and specific identification was performed by $2.5 \%$ agarose gel electrophoresis. Then, the products were sequenced only when each pair of primers showed a single objective band.

\subsection{Product purification and vector transform}

We used the fifth pair of primers to amplify the TRDMT1 promoter region using the Qinchuan cattle mixed pool as a template (Table 1). The complexity of the promoter base motif leads us to only obtain non-specific products. SanPrep Column DNA Gel Extraction Kit was used to purify the target sequence. PMD-19T vector was used to link purification and enrichment products. Mutations were introduced using the sixth and seventh pairs of primers (Table 2). Similarly, both 
Table 1. TRDMT1 promoter genetic variation detection primers.

\begin{tabular}{llrr}
\hline Fragment & Sequences $\left(5^{\prime}-3^{\prime}\right)$ & $\begin{array}{r}T_{\mathrm{m}} \\
\left({ }^{\circ} \mathrm{C}\right)\end{array}$ & $\begin{array}{r}\text { Product } \\
\text { size }(\mathrm{bp})\end{array}$ \\
\hline 1TRDMT1QD & $\begin{array}{l}\text { F: ACTGTGCATCAGGCATGTGA } \\
\text { R: TCCTGGGTACACTAGAGGGC }\end{array}$ & 57 & 393 \\
\hline \multirow{2}{*}{ 2TRDMT1QD } & $\begin{array}{l}\text { F: CTGCCCTGTGAAGACCTGAG } \\
\text { R: TAGTTCCGCGGCTTTTCAGT }\end{array}$ & 57 & 280 \\
\hline 3TRDMT1QD & $\begin{array}{l}\text { F: ACTCAAGCTAAGGCCCAACC } \\
\text { R: CTCAGGTCTTCACAGGGCAG }\end{array}$ & 57 & 339 \\
\hline \multirow{2}{*}{ 4TRDMT1QD } & $\begin{array}{l}\text { F: TTGGAGAAGGAAGGCCACAG } \\
\text { R: GACACTGTGCATCAGGCATG }\end{array}$ & 55 & 422 \\
\hline \multirow{2}{*}{ 5TRDMT1QD } & $\begin{array}{l}\text { F: GACCATTTCTGCTCCTCCC } \\
\text { R: GCCCTGTACCGTCTCACCT }\end{array}$ & - & 1468 \\
\hline
\end{tabular}

wild-type and mutant sequences were ligated to the $\mathrm{T}$ vector and transformed using the DH5 $\alpha$ competent state. The plasmids were extracted using the omega kit. All methods were performed according to the protocol.

\subsection{Digestion reaction and plasmid construction}

NheI and HindIII restriction endonucleases were used to digest the pGL3-Basic plasmid; we get the wild type product plasmid and the mutant product plasmid after digestion. The digestion products were purified and ligated into pGL3-Basic plasmid with Solution I.

\subsection{Cell transfection and transfection}

Human embryonic kidney (HEK) 293T cell was cultured in Dulbecco's modified Eagle's medium (DMEM) highglucose medium containing $10 \%$ fetal bovine serum (FBS) (Gibco, USA), supplemented with 100 units/mL penicillin, $0.1 \mathrm{mg} / \mathrm{mL}$ streptomycin, and incubated at $37^{\circ} \mathrm{C}$ in $5 \% \mathrm{CO}_{2}$. The cells were passaged every 1 to $2 \mathrm{~d}$. Before transfections, cells were seeded into 24 well plates at a density of $1 \times 10^{4}$ cells per well and incubated 1 to $2 \mathrm{~d}$. When the cell density was $80 \%$, it was replaced with antibiotic-free and serum-free DMEM/F12 medium (Gibco, USA) and incubated for $6 \mathrm{~h}$. The experiment was divided into four groups: $\mathrm{A}, \mathrm{B}, \mathrm{C}$ and D, which were transfected with pGL3-Control, pGL3-Basic, WT and Mut plasmids, respectively, with three replicates in each group. Transfection medium was prepared by mixing $4 \mu \mathrm{L}$ Lipofectamine 2000 with $0.8 \mu \mathrm{g}$ transfected plasmid and $10 \mathrm{ng}$ pRL-TK plasmid in $0.5 \mathrm{~mL}$ OPTI-MEM medium (Gibco, USA) and incubating the mixture for $20 \mathrm{~min}$ at room temperature. Transfection was carried out by substituting $0.5 \mathrm{~mL}$ from the DMEM/F12 medium covering the cells with the transfection mix. After $12 \mathrm{~h}$, the transfection medium was removed, covered with $1 \mathrm{~mL}$ OPTI-MEM medium.

\subsection{Dual-luciferase reporter gene assay}

According to a report by Derikx et al. (2015), $48 \mathrm{~h}$ after transfection, cells were rinsed with PBS. Relative luciferase activity was measured using Synergy H1 (BioTek, USA).

\subsection{Tissue expression profiling test}

RNA was extracted from different tissues of Qinchuan cattle by the TRIzol method. The cDNA was obtained by reverse transcription using the PrimeScript RT kit (TaKaRa, Kusatsu, Shiga Prefecture, Japan), and the concentration was controlled to a uniform $50 \mathrm{ng} / \mu \mathrm{L}$.

Primers of the TRDMT1 mRNA expression test were designed using Beacon Designer 8.14 software (Premier Biosoft International, Palo Alto, CA, USA), and glyceraldehyde-3-phosphate dehydrogenase (GAPDH) was used as an internal reference gene (Table 3 ). The reaction contained $100 \mathrm{ng}$ of $\mathrm{cDNA}, 10 \mu \mathrm{L} \mathrm{SYBR}^{\circledR}$ Premix Ex Taq TM II (TaKaRa, Japan) and 10 pmol of primers in a volume totaling $20 \mu \mathrm{L}$. The mixture was denatured for $30 \mathrm{~s}$ at $95^{\circ} \mathrm{C}$ and was followed by 40 cycles of $5 \mathrm{~s}$ at $95^{\circ} \mathrm{C}$ and $30 \mathrm{~s}$ at $60^{\circ} \mathrm{C}$.

\subsection{Statistical analysis}

Independent sample $t$ test was used to evaluate the relative the statistical significance of the differences in wild type and promoter variant of TRDMTl gene.

$P<0.05$ was considered significant. Based on the amplification efficiency of the target gene and the reference gene, according to the CT value obtained by qRT-PCR, a group close to the average value was selected as the control group. Then, the relative expression level was calculated using $2^{-\Delta \Delta \mathrm{Ct}}$. The GraphPad Prism 8.0 software (GraphPad Software Inc., San Diego, CA, USA) was used for the analysis. 
Table 2. TRDMT1 promoter introduced mutation primer.

\begin{tabular}{llc}
\hline Primer & Sequences $\left(5^{\prime}-3^{\prime}\right)$ & $T_{\mathrm{m}}\left({ }^{\circ} \mathrm{C}\right)$ \\
\hline \multirow{2}{*}{ Ftrdmt1gC } & $\begin{array}{l}\text { F1: ctaGCTAGCGACCATTTCTGCTCCTCCC } \\
\text { R1: GAGGCTATGGGGGAAGAGGTC }\end{array}$ & 64 \\
\hline \multirow{2}{*}{ Ltrdmt1gC } & $\begin{array}{l}\text { F2: GACCTCTTCCCCCATAGCCTC } \\
\text { R2: cccAAGCTTGCCCTGTACCGTCTCACCT }\end{array}$ & 64 \\
\hline
\end{tabular}

Table 3. The primers used for qPCR analysis.

\begin{tabular}{llc}
\hline Primer & Sequences $\left(5^{\prime}-3^{\prime}\right)$ & $\begin{array}{r}T_{\mathrm{m}} \\
\left({ }^{\circ} \mathrm{C}\right)\end{array}$ \\
\hline \multirow{2}{*}{ GAPDH } & $\begin{array}{l}\text { F1: CACCCTCAAGATTGTCAGCA } \\
\text { R1: GGTCATAAGTCCCTCCACGA }\end{array}$ & 56 \\
\hline \multirow{2}{*}{ TRDMT1 } & F2: TTTAATGAGCCCACCCTGTCA & 56 \\
& R2: TGTCCTTGGATCAGTCACATCA & 5 \\
\hline
\end{tabular}

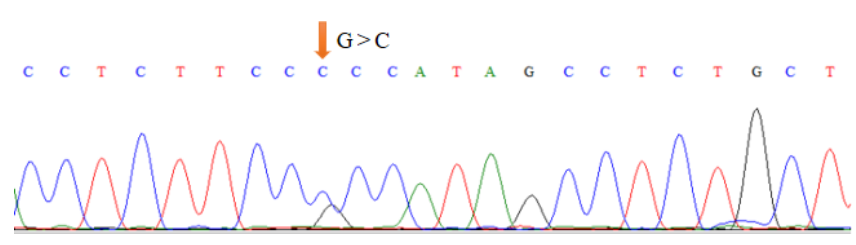

Figure 1. TRDMT1 promoter genetic variation site.

\section{Results}

\subsection{Genetic variation detection and introduction of promoter mutations of TRDMT1 promoter}

As shown in Table 1, the union set of the sequencing regions of the five pairs of primer amplification products was detected. We first discovered the $\mathrm{G}>\mathrm{C}$ mutation located upstream of the cattle TRDMTI translation initiator codon (Fig. 1). The transcription initiation site was predicted using the Promoter 2.0 Prediction Server software (http://www.cbs. dtu.dk/services/Promoter/, last access: 10 May 2019). The results showed that the -1216 was the transcription initiation site. Methylation island prediction (Li and Dahiya, 2002) showed that there was a methylation island between the first exon and -725 (Fig. 2), suggesting that this position may be involved in the regulation of gene expression. We have set up gradient PCR, but unfortunately the fifth pair of primers in Table 1 can only produce non-specific amplification products.

\subsection{Predicting promoter variation and transcription factor binding difference}

The Ftrdmt1gC and Ltrdmt1gC amplification products were diluted 50-fold respectively and used as a template. FtrdmtlgC F was used as the upstream primer, and
Ltrdmt $1 \mathrm{gC} \mathrm{R}$ was used as the downstream primer. After PCR amplification, we obtained the mutant promoter sequence. After vector sequencing, the accuracy of all fragments ligated into the $\mathrm{T}$ vector in the experiment was confirmed. The combination of TRANSFAC and Genomatix found that the $\mathrm{G}>\mathrm{C}$ mutation may cause a difference in binding between the transcription factor $\mathrm{Sp1}$, the pleomorphic adenoma gene (PLAG1), the zinc finger protein (ZNF35) and the bone marrow zinc finger 1 factor (MZF1) transcription factor (Figs. 3 and 4).

\subsection{Double luciferase activity analysis of TRDMT1 promoter genetic variation}

Promoter activity of different genotypes of TRDMT1 was assessed using luciferase reporter gene expression. After calibration by the control group and the basic group, the results showed that the relative activity of the mutant promoter was 1.4 times that of the wild type $(P<0.05)$ (Fig. 5$)$.

\subsection{The tissue expression profile of TRDMT1 in Qinchuan cattle}

Heart, spleen, kidney, rumen, liver, lung, small intestine and muscle tissues were utilized to detect the expression of the TRDMT1 gene. The result showed the different expression levels in each tissue. The result revealed that TRDMT1 was differentially expressed in the different tissues. Its expression is significantly higher in lung than in other tissues $(p<0.01)$, followed by the highest expression in rumen $(p<0.05)$, and the lowest expression in muscle and liver. There was no significant difference in the expression level among other tissues. the lowest in the fetal cattle, but the difference in calves and adult cattle stage was not statistically significant $(p>0.05)$ (Fig. 6).

\section{Discussion}

As an apparent modifier, TRDMT1 can chemically modify not only DNA but also a specific tRNA subgroup modifier. The occurrence of modification affects life activities by affecting protein synthesis. Liu et al. (2015) reported that the SNP locus of DNA chemical modifier DNMT family gene is related to carcass quality, lean color, flanks thickness and other traits. The TRDMT1 gene is relatively conserved in the 


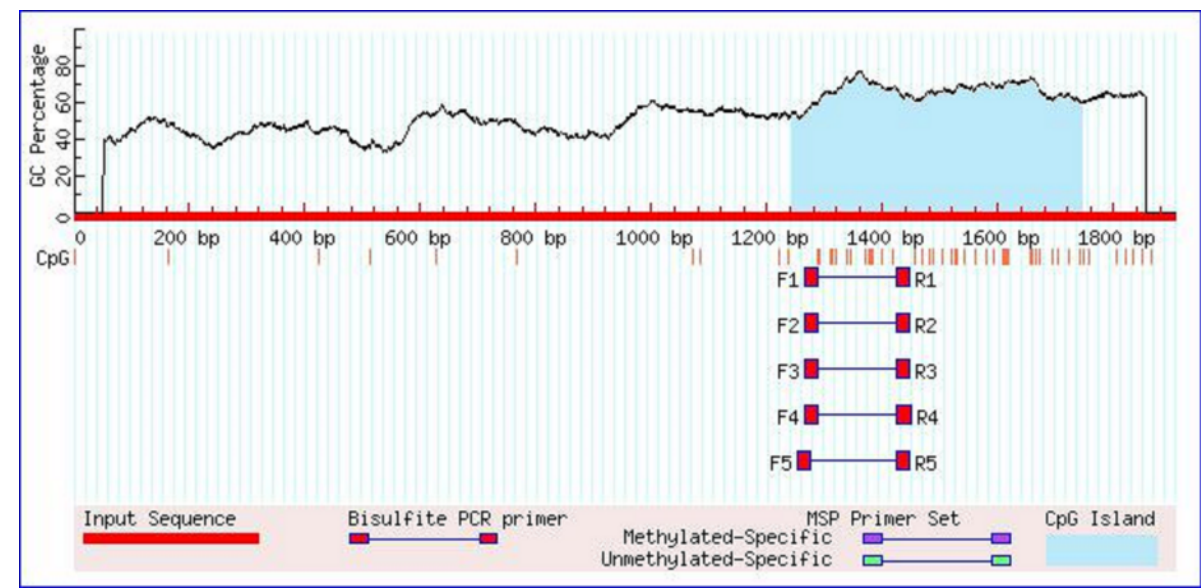

Figure 2. Prediction result of the $\mathrm{CpG}$ island in the TRDMT1 promoter region.

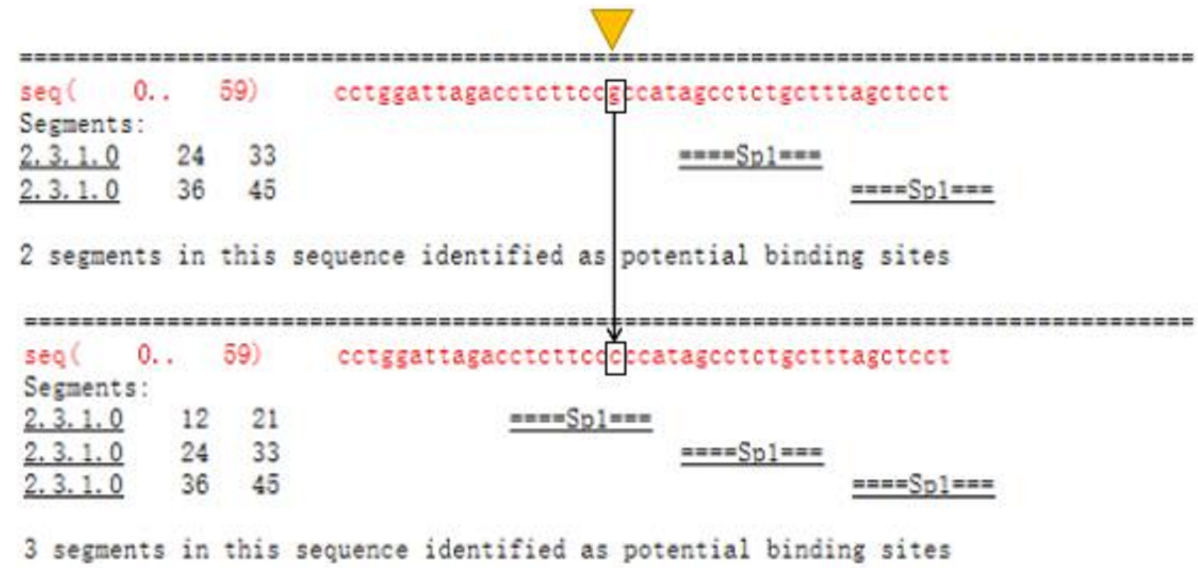

Figure 3. TRANSFAC predicts differences in promoter variation and transcription factor binding.

biological evolution process. Although it is named tRNA aspartate methyltransferase 1, Tuorto et al. (2012) constructed an RNA bisulfite sequencing map and found that the mouse TRDMTl gene has an effect on tRNA-AspGTC and tRNA. tRNA-ValAAC, tRNA-GlyGCC and tRNA-LeuCAA all have a methyl modification at position $\mathrm{C} 38$, and the modified tRNA subgroups may be tRNAs that connect mRNA and protein during the translation of most proteins in life activities. TRDMT1 gene mediates tRNA through modification selfstability and reduces misreading during protein translation. Gene function verification in mice showed that TRDMT1 expression is related to embryonic bone development and brain development (Tuorto et al., 2012). In zebrafish gene function verification, TRDMT1 is related to the development of tissues such as the retina and brain (Rai et al., 2007). The tRNA modification genes are evolutionarily conserved, but most studies only exist at the level of model animals such as yeast and mice, and there is a lack of functional studies on the tRNA modification genes of large animals, such as cattle and sheep.
In this study, initially we used Promoter 2.0 Prediction Server software to predict that the transcription start site of the bovine TRDMT1 gene is the promoter region -1216 . Then we used mixed-pool sequencing to scan the $\mathrm{G}>\mathrm{C}$ mutation at the promoter region -1223 polymorphic loci. For different genotype sequence models, we used TRANSFAC to predict the binding sites of transcription factors and found that $\mathrm{G} / \mathrm{C}$ mutation may cause a difference in the binding of basic transcription factor $\mathrm{sp} 1$ (Fig. 3). The sp1 transcription factor belongs to the sp protein family and is the most abundant type of transcription factor in cells. Sp1 has a certain preference for binding to GC-rich promoters (Kadonaga et al., 1986). As a nucleoprotein, sp1 expression changes during development, and sp1 knockout mice exhibit embryonic lethality (Letovsky and Dynan, 1989). Sp1 is involved in the regulation of the cell cycle, and its protein level is reduced in senescent cells, and its expression level is also related to some cancers (Oh et al., 2007; Takami et al., 2007; Safe and Abdelrahim, 2005). We speculate that the expression level of sp1 protein in each tissue cell is the same among cattle in- 


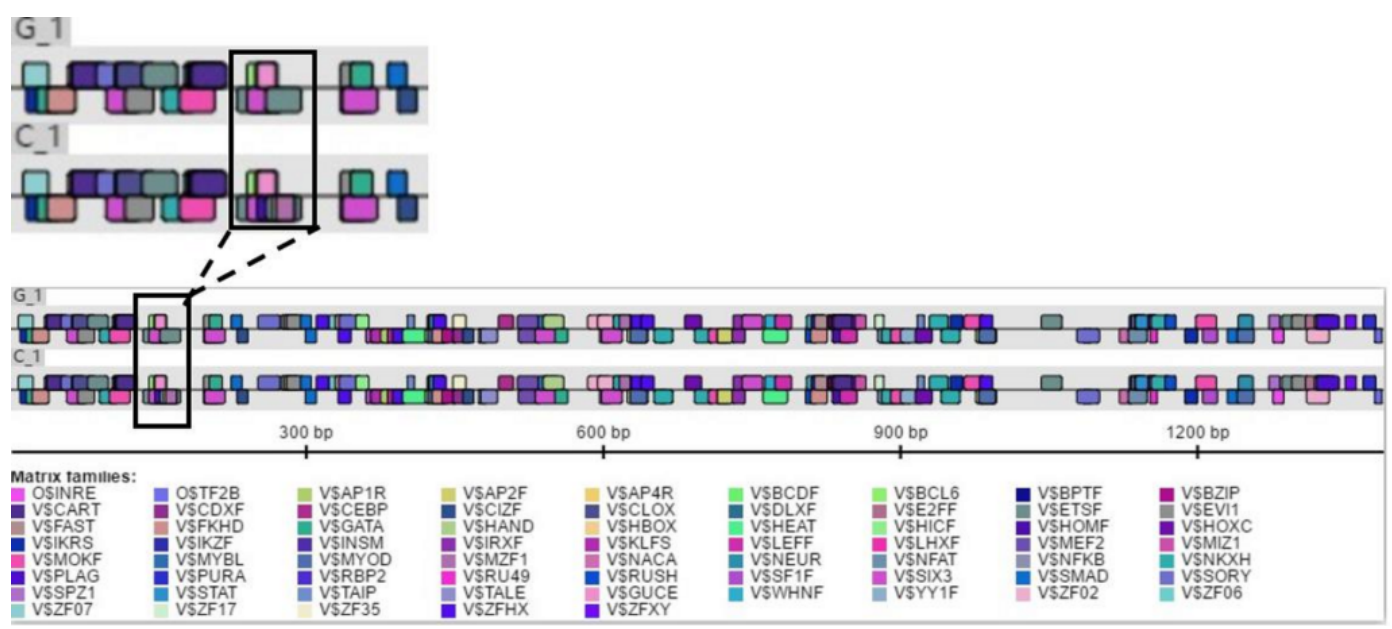

Figure 4. Genomatix predicts differences in promoter variation and transcription factor binding.

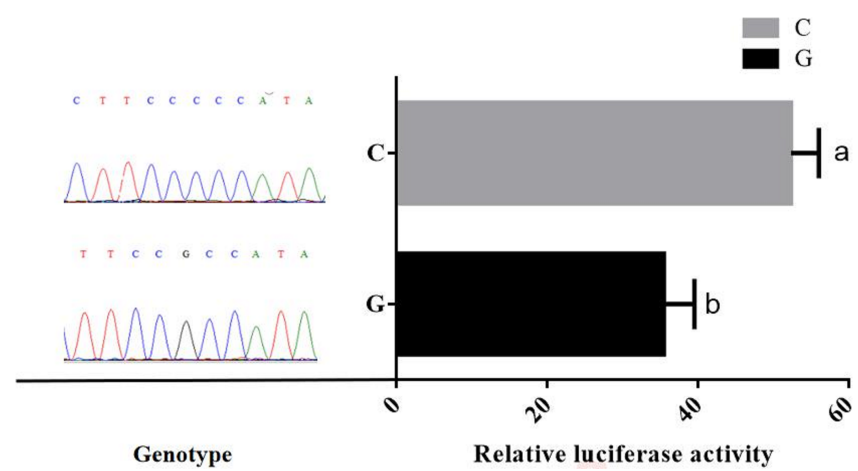

Figure 5. Comparison of relative luciferase activity of TRDMT1 promoter variant.

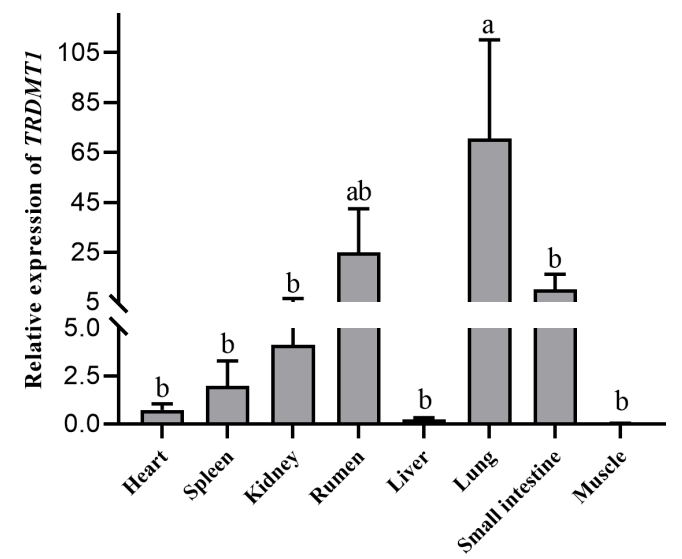

Figure 6. Expression profiling of the TRDMT1 gene in Qinchuan cattle.

dividuals during the same period. The change of gene motif leads to the deletion of sp1 binding site and may downregulate the gene expression level. Then we used Genomatix to predict transcription factor binding and found the following:
$\mathrm{G}>\mathrm{C}$ mutation may increase the binding of the pleomorphic adenoma gene PLAG1, zinc finger protein ZNF35 and the bone marrow zinc finger 1 factor MZF1 transcription factor (Fig. 4), suggesting that the TRDMT1 gene may also be the target gene regulated by PLAG1. Tang et al. (2013) reported that PLAG1 regulates the expression of IGF2 and affects human embryonic development. The PLAG1 gene has a $96.4 \%$ homology to humans, suggesting that the PLAGl gene structure is similar to humans and may participate in its expression regulation as a potential transcription factor for the TRDMTI gene.

The conservation of tRNA-modified gene structures in eukaryotes suggests similar functions and regulatory roles (Hopper and Phizicky, 2003). The effect of the TRDMT1 gene on zebrafish and mouse development leads us to care about its effects on livestock development (Rai et al., 2007). In yeast experiments, the modified genes produced few phenotypes except for the tRNA anticodon loop region. But the TRDMT1 gene modifies a specific tRNA subpopulation in the anticodon loop. In addition to mutant construction, the phenotypic effects produced by differences in gene expression levels are also a method of reflecting gene function. Differences in the transcriptional activity of genetic promoter genetic variants can be indirectly identified by dual-luciferase assays. Establishing the relationship between genetic variation and expression was also important for the protection of germplasm resources and the development of genetic resources. Hence, we performed a dual-luciferase assay. We used $293 \mathrm{~T}$ cells for verification, which has the characteristics of high transfection efficiency and easy culture. However, 293T cells are derived from humans. As an experiment material, it was able to analyze the transcription factors shared by eukaryotic cells, but they did not reflect the endogenous characteristics unique to the cattle. The differential binding of transcription factors showed that the genetic variation of this site caused a difference in the activity 
of bovine TRDMT1 promoter, which may cause a difference in the expression level of TRDMT1. In addition, we found a correlation between the strong linkage structure of bovine TRDMT1 exon genetic variation and the growth traits of cattle (data not published). It was suggested that the expression level and structural variation of bovine TRDMT1 gene may have a potential impact on its growth and development. Although we predicted that the transcriptional factors of the TRDMT1 promoter may cause differential binding, transfection of different genotypes into $293 \mathrm{~T}$ cells showed that the variant affected its transcriptional activity at the eukaryotic level, but we were not sure which transcription factors are differentially combined, suggesting that the use of different tissues of the cattle to study the promoter variant structure is important for regulating the expression of the TRDMTl gene.

Due to the complexity of the sequence structure of the bovine TRDMT1 promoter region, the test predicts the promoter region by transcription start site prediction and $\mathrm{CpG}$ island position prediction. The promoter truncation vectors were not constructed, and the specific position of the TRDMT1 gene core promoter was not explored. The dualluciferase vectors pGL3-Basic (G) and pGL3-Basic (C) were constructed, both of which represent the region of the TRDMT1 promoter $-1387 /+81$ fragment. Excessive fragments may result in decreased transcriptional activity and regulation of transcriptional repressors. However, the results of the experiment indicated that the $\mathrm{G}>\mathrm{C}$ mutation at the -1223 bp position upstream of the TRDMTI translation initiator codon caused a difference in the transcriptional activity (Fig. 5). When the promoter region of bovine TRDMT1 gene was in the $\mathrm{C}$ genotype, the transcriptional activity of the gene was significantly higher than that of the G genotype. It was suggested that the $\mathrm{G}>\mathrm{C}$ mutation may affect the binding activity of key transcription factors in the promoter region of bovine TRDMTI gene and affect the transcription level of the gene.

In the past, TRDMT1 gene function studies were restricted to model animals such as mice and zebrafish. The research of TRDMT1 gene function mainly involved interference, inhibition, knockdown and knockout experiments and did not overexpress the expression of TRDMTI. The study of the charge of tRNA modification was lacking. The modification of tRNA and the translation of protein did not establish a comprehensive and accurate correspondence. The related studies did not respond to cell fate led by sufficient or excess tRNA modification. In this experiment, mixed-pool sequencing technology was used to find that there was a $\mathrm{G}>\mathrm{C}$ mutation in the promoter region -1223 of the yellow cattle TRDMT1 gene. Fluorescent recombinant plasmids of different genotypes were constructed at this site. The transfected 293T cells were analyzed, and the relative fluorescence intensity was analyzed. The fluorescence intensity is significantly higher than that of wild-type G. Through software analysis, the mutation is located near the transcription start site, and the $\mathrm{C}$ allele increases the possibility of the binding of tran- scription factors such as sp1, PLAG1, ZNF35 and MZF1 and affects the transcriptional regulation of bovine TRDMTI and detected the relative expression of TRDMT1 gene in each tissue. This study provides a theoretical basis for the study of livestock TRDMT1 gene expression on its life activities and the study of tRNA modification in animal life processes.

Ethics statement. The China Council on Animal Care guidelines were used when dealing with animals in all steps of experiments. All experiments implemented were approved by the Committee of the Northwest A\&F University (IACUC-NWAFU) and fully followed local animal welfare guidelines, laws and policies.

Data availability. No data sets were used in this article.

Author contributions. Data curation was done by MW and SW, formal analysis by SL, funding acquisition by XS, project administration by XS, resources by HZ, and writing of the original draft by $\mathrm{XY}$ and $\mathrm{SH}$.

Competing interests. The authors declare that they have no conflict of interest.

Acknowledgements. We thank Xianyong Lan and Sihuan Zhang for providing the pGL3-Basic, pGL3-Control and pRL-TK plasmids.

Financial support. This research was supported financially by the Agriculture Research System of China (grant no. CARS-34), the Key Research and Development Projects of Shaanxi Province (grant no. 2018ZDXM-NY-040), and the Integrated Demonstration Project of Key Technologies for Cattle and Sheep Breeding and Farming in Farming-Pastoral Ecotone of the Ministry of Agriculture and Rural Affairs of the People's Republic of China (grant no. 16190050).

Review statement. This paper was edited by Steffen Maak and reviewed by Yun Ma and one anonymous referee.

\section{References}

Alexandrov, A., Chernyakov, I., Gu, W., Hiley, S. L., Hughes, T. R., Grayhack, E. J., and Phizicky, E. M.: Rapid tRNA decay can result from lack of nonessential modifications, Mol. Cell, 21, 8796, https://doi.org/10.1016/j.molcel.2005.10.036, 2006.

Barrett, J. C., Hansoul, S., Nicolae, D. L., Cho, J. H., Duerr, R. H., Rioux, J. D., Brant, S. R., Silverberg, M. S., Taylor, K. D., Barmada, M. M., Bitton, A., Dassopoulos, T., Datta, L. W., Green, T., Griffiths, A. M., Kistner, E. O., Murtha, M. T., Regueiro, M. D., Rotter, J. I., Schumm, L. P., Steinhart, A. H., Targan, S. R., 
Xavier, R. J., Consortium, N. I. G., Libioulle, C., Sandor, C., Lathrop, M., Belaiche, J., Dewit, O., Gut, I., Heath, S., Laukens, D., Mni, M., Rutgeerts, P., Gossum, A, V., Zelenika, D., Franchimont, D., Hugot, J. P., Vos, M. D., Vermeire, S., Louis, E., Consortium, B. F. I., Consortium, W. T. C. C., Cardon, L. R., Anderson, C. A., Drummond, H., Nimmo, E., Ahmad, T., Prescott, N. J., Onnie, C. M., Fisher, S. A., Marchini, J., Ghori, J., Bumpstead, S., Gwilliam, R., Tremelling, M., Deloukas, P., Mansfield, J., Jewell, D., Satsangi, J., Mathew, C, G., Parkes, M., Georges, M., and Daly, M. J: Genome-wide association defines more than 30 distinct susceptibility loci for Crohn's disease, Nat. Genet., 40, 955-962, https://doi.org/10.1038/ng.175, 2008.

Bohnsack, K. E., Höbartner, C., and Bohnsack, M. T.: Eukaryotic 5-methylcytosine (m5C) RNA Methyltransferases: Mechanisms, Cellular Functions, and Links to Disease, Genes, 10, 102, https://doi.org/10.3390/genes10020102, 2019.

Cătoi, A. F., Pârvu, A., Mureşan, A., and Busetto, L.: Metabolic Mechanisms in Obesity and Type 2 Diabetes: Insights from Bariatric/Metabolic Surgery, Obesity Facts, 8, 350-363, https://doi.org/10.1159/000441259, 2015.

Chen, H., Yang, H., Zhu, X., Yadav, T., Ouyang, J., Truesdell, S. S., Tan, J., Wang, Y., Duan, M., Wei, L., Zou, L., Levine, A. S., Vasudevan, S., and Lan, L.: m5C modification of mRNA serves a DNA damage code to promote homologous recombination, Nat. Commun., 11, 2834, https://doi.org/10.1038/s41467-020-167227, 2020.

Derikx, M. H., Geisz, A., Kereszturi, É., and Sahin-Tóth, M.: Functional significance of SPINK1 promoter variants in chronic pancreatitis, American journal of physiology, Gastrointestinal and Liver Physiology, 308, G779-G784, https://doi.org/10.1152/ajpgi.00022.2015, 2015.

Franke, B., Vermeulen, S. H., Steegers-Theunissen, R. P., Coenen, M. J., Schijvenaars, M. M., Scheffer, H., den Heijer, M., and Blom, H. J.: An association study of 45 folate-related genes in spina bifida: Involvement of cubilin (CUBN) and tRNA aspartic acid methyltransferase 1 (TRDMT1), Birth Defects Res. A, 85, 216-226, https://doi.org/10.1002/bdra.20556, 2009.

Goll, M. G., Kirpekar, F., Maggert, K. A., Yoder, J. A., Hsieh, C. L., Zhang, X., Golic, K. G., Jacobsen, S. E., and Bestor, T. H.: Methylation of tRNAAsp by the DNA methyltransferase homolog Dnmt2, Science, 311, 395-398, https://doi.org/10.1126/science.1120976, 2006.

Grosjean, H., Breton, M., Sirand-Pugnet, P., Tardy, F., Thiaucourt, F., Citti, C., Barré, A., Yoshizawa, S., Fourmy, D., de Crécy-Lagard, V., and Blanchard, A.: Predicting the minimal translation apparatus: lessons from the reductive evolution of mollicutes, PLoS Genet., 10, e1004363, https://doi.org/10.1371/journal.pgen.1004363, 2014.

Hopper, A. K. and Phizicky, E. M.: tRNA transfers to the limelight, Gene. Dev., 17, 162-180, https://doi.org/10.1101/gad.1049103, 2003.

Jurkowski, T. P., Meusburger, M., Phalke, S., Helm, M., Nellen, W., Reuter, G., and Jeltsch, A.: Human DNMT2 methylates tRNA(Asp) molecules using a DNA methyltransferase-like catalytic mechanism, RNA, 14, 16631670, https://doi.org/10.1261/rna.970408, 2008.

Kadonaga, J. T., Jones, K. A., and Tjian, R.: Promoter-specific activation of rna polymerase ii transcription by $\mathrm{sp} 1$, Trends in Biochemical ences, 11, 20-23, https://doi.org/10.1016/09680004(86)90226-4, 1986.

Kunert, N., Marhold, J., Stanke, J., Stach, D., and Lyko, F.: A Dnmt2-like protein mediates DNA methylation in Drosophila, Development, 130, 5083-5090, https://doi.org/10.1242/dev.00716, 2003.

Letovsky, J. and Dynan, W. S.: Measurement of the binding of transcription factor $\mathrm{Sp} 1$ to a single GC box recognition sequence, Nucleic Acids Res., 17, 2639-2653, https://doi.org/10.1093/nar/17.7.2639, 1989.

Li, L. C. and Dahiya, R.: MethPrimer: designing primers for methylation PCRs, Bioinformatics, 18, 1427-1431, https://doi.org/10.1093/bioinformatics/18.11.1427, 2002.

Li, M. J., Liu, M., Liu, D., Lan, X. Y., Lei, C. Z., Yang, D. Y., and Chen, H.: Polymorphisms in the Promoter Region of the Chinese Bovine PPARGC1A Gene, Asian-Austral. J. Anim., 26, 483-487, https://doi.org/10.5713/ajas.2012.12554, 2013.

Liu, X., Usman, T., Wang, Y., Wang, Z., Xu, X., Wu, M., Zhang, Y., Zhang, X., Li, Q., Liu, L., Shi, W., Qin, C., Geng, F., Wang, C., Tan, R., Huang, X., Liu, A., Wu, H., Tan, S., and $\mathrm{Yu}, \mathrm{Y}$.: Polymorphisms in epigenetic and meat quality related genes in fourteen cattle breeds and association with beef quality and carcass traits, Asian-Austral. J. Anim., 28, 467-475, https://doi.org/10.5713/ajas.13.0837, 2015.

Oh, J. E., Han, J. A., and Hwang, E. S.: Downregulation of transcription factor, $\mathrm{Sp} 1$, during cellular senescence, Biochem. Bioph. Res. Co., 353, 86-91, https://doi.org/10.1016/j.bbrc.2006.11.118, 2007.

Pang, Y., Wang, J., Zhang, C., Lei, C., Lan, X., Yue, W., Gu, C., Chen, D., and Chen, H.: The polymorphisms of bovine VEGF gene and their associations with growth traits in Chinese cattle, Mol. Biol. Rep., 38, 755-759, https://doi.org/10.1007/s11033010-0163-6, 2011.

Pütz, J., Florentz, C., Benseler, F., and Giegé, R.: A single methyl group prevents the mischarging of a tRNA, Nat. Struct. Biol., 1, 580-582, https://doi.org/10.1038/nsb0994-580, 1994.

Rai, K., Chidester, S., Zavala, C. V., Manos, E. J., James, S. R., Karpf, A. R., Jones, D. A., and Cairns, B. R.: Dnmt2 functions in the cytoplasm to promote liver, brain, and retina development in zebrafish, Gene. Dev., 21, 261-266, https://doi.org/10.1101/gad.1472907, 2007.

Safe, S. and Abdelrahim, M.: Sp transcription factor family and its role in cancer, Eur. J. Cancer, 41, 2438-2448, https://doi.org/10.1016/j.ejca.2005.08.006, 2005.

Sarin, L. P. and Leidel, S. A.: Modify or die? - RNA modification defects in metazoans, RNA Biol., 11, 1555-1567, https://doi.org/10.4161/15476286.2014.992279, 2014.

Schaefer, M., Pollex, T., Hanna, K., Tuorto, F., Meusburger, M., Helm, M., and Lyko, F.: RNA methylation by Dnmt2 protects transfer RNAs against stress-induced cleavage, Gene. Dev., 24, 1590-1595, https://doi.org/10.1101/gad.586710, 2010.

Sibbritt, T., Patel, H. R., and Preiss, T.: Mapping and significance of the mRNA methylome. Wiley interdisciplinary reviews, RNA, 4, 397-422, https://doi.org/10.1002/wrna.1166, 2013.

Schumann, U., Zhang, H. N., Sibbritt, T., Pan, A., Horvath, A., Gross, S., Clark, S. J., Yang, L., and Preiss, T.: Multiple links between 5-methylcytosine content of mRNA and translation, BMC Biol., 18, 40, https://doi.org/10.1186/s12915-020-00769$5,2020$. 
Takami, Y., Russell, M. B., Gao, C., Mi, Z., Guo, H., Mantyh, C. R., and Kuo, P. C.: Sp1 regulates osteopontin expression in SW480 human colon adenocarcinoma cells, Surgery, 142, 163169, https://doi.org/10.1016/j.surg.2007.02.015, 2007.

Tang, Q., Wu, W., Xu, X., Huang, L., Gao, Q., Chen, H., Sun, H., Xia, Y., Sha, J., Wang, X., Chen, D., and $\mathrm{Xu}$, Q.: miR-141 contributes to fetal growth restriction by regulating PLAG1 expression, PloS one, 8, e58737, https://doi.org/10.1371/journal.pone.0058737, 2013.

Tuorto, F., Liebers, R., Musch, T., Schaefer, M., Hofmann, S., Kellner, S., Frye, M., Helm, M., Stoecklin, G., and Lyko, F.: RNA cytosine methylation by Dnmt2 and NSun2 promotes tRNA stability and protein synthesis, Nat. Struct. Mol. Biol., 19, 900-905, https://doi.org/10.1038/nsmb.2357, 2012.
Vojta, A., Dobrinić, P., Tadić, V., Bočkor, L., Korać, P., Julg, B., Klasić, M., and Zoldoš, V.: Repurposing the CRISPR-Cas9 system for targeted DNA methylation, Nucleic Acids Res., 44, 5615-5628, https://doi.org/10.1093/nar/gkw159, 2016.

Xue, S., Xu, H., Sun, Z., Shen, H., Chen, S., Ouyang, J., Zhou, Q., Hu, X., and Cui, H.: Depletion of TRDMT1 affects 5methylcytosine modification of mRNA and inhibits HEK293 cell proliferation and migration, Biochem. Bioph. Res. Co., 520, 60 66, https://doi.org/10.1016/j.bbrc.2019.09.098, 2019. 